\title{
Factors associated with intrusive cancer-related worries in women undergoing cancer genetic risk assessment
}

\author{
Paul Bennett · Clare Wilkinson · Jim Turner • \\ Rhiannon Tudor Edwards · Barbara France · \\ Gethin Griffith · Jonathon Gray
}

Published online: 11 June 2009

(C) Springer Science+Business Media B.V. 2009

\section{Erratum to: Familial Cancer (2009) 8:159-165 \\ DOI 10.1007/s10689-008-9221-9}

Unfortunately in Familial Cancer (2009) 8:159-165, one of the co-author's name had been misspelled. The correct version is Gethin Griffith and not Gethin Griffin as published. It also appears incorrectly in the table of contents entry for the article "Factors associated with intrusive cancer-related worries in women undergoing cancer genetic risk assessment".

The online version of the original article can be found under doi: 10.1007/s10689-008-9221-9.

P. Bennett $(\bowtie)$

Nursing, Health and Social Care Research Centre, University of

Cardiff, Eastgate House 4th Floor, 35-43 Newport Road,

CF24 0AB Cardiff, UK

e-mail: bennettp1@ cardiff.ac.uk

C. Wilkinson - J. Turner · B. France

Department of Primary Care and Public Health,

University of Cardiff, Cardiff, UK

R. T. Edwards

University of Wales, Bangor, UK

G. Griffith

Brunel University, Uxbridge, UK

J. Gray

Institute of Medical Genetics, Cardiff University, Cardiff, UK 